\title{
Comparative Study for the Production of Mycophenolic Acid using Penicillium brevicompactum in Batch, Fed- batch and Continuous Fermentation Process
}

\author{
Shubhankar Anand 1 (D), Pradeep Srivastava 1,* (D) \\ 1 School of Biochemical Engineering, Indian Institute of Technology (Banaras Hindu University), Varanasi- 221005, India; \\ shubh048@gmail.com (S.A), pksrivastava.bce@itbhu.ac.in (P.S); \\ * Correspondence: pksrivastava.bce@itbhu.ac.in;
}

Received: 22.02 2021; Revised: 25.03.2021; Accepted: 29.03.2021;

\begin{abstract}
Mycophenolic acid (MPA) is, due to its immunosuppressive and biological activities, a potential compound. It is the secondary metabolite produced in submerged cultivation by the microfungus Penicillium brevicompactum. Batch, fed-batch, and continuous mode of cultivation for mycophenolic acid production were performed and compared in the current work. To increase productivity, mycophenolic acid production was studied in batch, fed-batch, and continuous bioreactors. These experiments were conducted with a $2.5 \mathrm{~L}$ working volume in a $3.7 \mathrm{~L}$ continuous stirred tank bioreactor. In all cases, operating conditions such as temperature, $\mathrm{pH}$, agitation, and aeration, $28{ }^{\circ} \mathrm{C}, 5.5,200 \mathrm{rpm}$, and $2 \mathrm{vvm}$, respectively, were the same. In fed-batch fermentation, the MPA concentration obtained was $1.91 \mathrm{~g} / \mathrm{L}$ higher than the value obtained in batch culture, $1.55 \mathrm{~g} / \mathrm{L}$, while in continuous fermentation, $1.67 \mathrm{~g} / \mathrm{L}$ was obtained. The mycophenolic acid productivity obtained in the continuous fermentation process was $0.025 \mathrm{~g} / \mathrm{L} / \mathrm{h}$, which was maximum MPA productivity, compared to $0.007 \mathrm{~g} / \mathrm{L} / \mathrm{h}$ in the fed-batch fermentation process and $0.006 \mathrm{~g} / \mathrm{L} / \mathrm{h}$ in the batch fermentation process. The impact of substrate inhibition on the product formation can effectively bring down by continuous fermentation processes. The MPA productivity was increased in continuous fermentation relative to batch and fed-batch processing. The finding indicates that continuous culture of Penicillium brevicompactum is a promising strategy for the synthesis of mycophenolic acid.
\end{abstract}

Keywords: batch; fed-batch; continuous fermentation; mycophenolic acid; productivity.

(C) 2021 by the authors. This article is an open-access article distributed under the terms and conditions of the Creative Commons Attribution (CC BY) license (https://creativecommons.org/licenses/by/4.0/).

\section{Introduction}

In recent years, microbial metabolites have become a hotspot of scientific research. Secondary metabolites are mainly isolated from a microbial source [1-2]. Pharmaceutical industries commonly use several fungal fermentation processes for the large-scale production of drugs [3-4]. Mycophenolic acid (6-(4-hydroxy-6-methoxy methyl 3oxophthalanyl)-4methyl-4-hexenoic acid, $\left.\mathrm{C}_{17} \mathrm{H}_{20} \mathrm{O}_{6}, \quad \mathrm{MPA}\right)$ is one of the commonly prescribed immunosuppressive drug produced by the fermentation process [5-6]. The first secondary metabolite [7], mycophenolic acid isolated from the fermentation broth of several species of Penicillium [8-9] and other fungi [10-11]. Mycophenolate mofetil (MMF) and sodium mycophenolate, derivatives of MPA are commonly used as immunosuppressors in organs and tissues transplantation [12-13]. Both are used to treat numerous allergic, cancer, and fungal diseases [14-15]. MMF was approved as an immunosuppressive drug for reducing the chances 
of graft rejection after organ transplantation in 1995 by the food and drug administration (FDA) [16-17]. Mycophenolic acid has an anti-proliferative activity that inhibits the enzyme inosine monophosphate dehydrogenase (IMPDH) [18]. Inosine monophosphate dehydrogenase plays an important role in the de novo biosynthetic pathway of purine nucleotides [19-20]. The proliferation of B and T lymphocytes [21-22], which rely exclusively on IMPDH dependent pathway for nucleotide synthesis, is inhibited in the presence of mycophenolic acid [23-24]. Most other cell types use IMPDH independent salvage pathway for this synthesis [13,25]. For this cause, similar to other immunosuppressive medications, MPA is highly selective and has fewer side effects [26-27].

Many authors have published their work on strain improvement by mutation to increase the MPA production; hardly any attention has been given to developing the fermentation method [28-29]. The highest MPA concentration $5.7 \mathrm{~g} / \mathrm{L}$ was observed by $\mathrm{Xu}$ et al. using immobilized cells in a rotating fibrous bed bioreactor [30]. For pilot-scale and industrial purpose usage, these bioreactors are still unsuitable. In the industrial fermentation process, continuously stirred tank bioreactors to have a proven history of practical use. We report MPA production by batch, fed-batch, and continuous fermentation in stirred tank bioreactors in this work. To increase the final concentration of the substance, various feeding methods were discussed.

Production of MPA mainly begins during the stationary period of fungal growth [31]. MPA is the Non-growth associated, extracellular product [32]. Thus, the general development plan produces a high biomass concentration when the stationary phase was reached and reduced cell autolysis [33]. To achieve the highest cell biomass density in the stationary phase of fermentation, a suitable feeding strategy plays a crucial role [34-35]. Some studies reported that precursors of MPA, methionine, and glycine feeding could increase the MPA concentration in fermentation broth [8]. Another element that has also played an important role in microbial growth and metabolites' aggregation is culture $\mathrm{pH}$ [36-37]. The impact of $\mathrm{pH}$ and feeding methodologies for various fermentations is significant [38-39].

In this work, an optimized medium was used for the production of MPA using Penicillium brevicompactum. Here we examine various cultivation strategies on MPA production in a $3.7 \mathrm{~L}$ bench-scale continuous stirred tank bioreactor using the same microorganism. This study's main objective was to compare MPA production and productivity in Batch fermentation, fed-batch, and continuous fermentation processes.

\section{Materials and Methods}

\subsection{Microorganism and Inoculum preparation.}

In this work, the microfungus Penicillium brevicompactum MTCC 549 was used and collected from the Institute of Microbial Technology (IMTech) Chandigarh, India. Czapek Dox agar medium was used aseptically to prepare the stock culture of $P$. brevicompactum MTCC 549. The slants were stored at $4{ }^{\circ} \mathrm{C}$. As previously mentioned [40], a spore suspension was prepared and used as an inoculum.

\subsection{Cultivation medium composition.}

The optimized medium was used for the production of MPA using Penicillium brevicompactum. The optimized fermentation culture medium composition for the production of MPA had the following elements: glucose- $60 \mathrm{~g} / \mathrm{L}$, glycine- $9 \mathrm{~g} / \mathrm{L}$, enzymatically hydrolyzed 
casein- $15 \mathrm{~g} / \mathrm{L}$, methionine- $0.5 \mathrm{~g} / \mathrm{L}$, potassium dihydrogen phosphate- $5 \mathrm{~g} / \mathrm{L}$, magnesium sulfate heptahydrate- $1 \mathrm{~g} / \mathrm{L}$, and the trace element solution- $1 \mathrm{~mL} / \mathrm{L}$. Trace element mixture contained: $\mathrm{FeSO}_{4} .7 \mathrm{H}_{2} \mathrm{O}-2.2 \mathrm{~g} / \mathrm{L}, \mathrm{CuSO}_{4} .5 \mathrm{H}_{2} \mathrm{O}-0.3 \mathrm{~g} / \mathrm{L}, \mathrm{ZnSO}_{4} .7 \mathrm{H}_{2} \mathrm{O}-2.4 \mathrm{~g} / \mathrm{L}, \mathrm{MnSO}_{4} .4 \mathrm{H}_{2} \mathrm{O}-$ $0.16 \mathrm{~g} / \mathrm{L}$, and $\mathrm{KMoO}_{4}-0.2 \mathrm{~g} / \mathrm{L} .2 \mathrm{M} \mathrm{HCl}$ or $2 \mathrm{M} \mathrm{NaOH}$ was used to maintain the $\mathrm{pH}$ of the media at 5.5. All the medium components were separately autoclaved at $121{ }^{\circ} \mathrm{C}$ for $15 \mathrm{~min}$ except glycine, methionine, and trace elements mixture. The trace element solution, glycine, and methionine were sterilized using a sterile $0.2 \mu \mathrm{m}$ membrane filter (Axiva).

\subsection{Analytical methods.}

\subsubsection{Biomass concentration.}

The dry cell weight approach was used to quantify dry fungal cell mass in the fermentation broth. To investigate the dry cell weight of fungal biomass, five-milliliter samples were collected every after $24 \mathrm{~h}$ intervals. The obtained sample was centrifuged at $5000 \mathrm{rpm}$ first and then dried in a hot air oven at $90{ }^{\circ} \mathrm{C}$ for at least overnight or until it reached a steady weight.

\subsubsection{Glucose concentration.}

The evaluation of glucose concentration in the collected samples was carried out using the dinitrosalicylic acid (DNS) method defined by Miller et al. [41]. The absorbance of the samples was measured by UV spectrophotometer (Shimadzu, Japan) at a wavelength of 540 $\mathrm{nm}$.

\subsubsection{Mycophenolic acid concentration.}

The concentration of mycophenolic acid, produced by fermentation of Penicillium brevicompactum was examined by high-performance liquid chromatography (HPLC) at a wavelength of $220 \mathrm{~nm}$, as described in our earlier study [40].

All the analysis was performed in triplicate. All important parameters' optimum values were described except constant parameters such as $\mathrm{pH}$, temperature, agitation rate, aeration rate, and dissolved oxygen concentration.

\subsection{Specifications of 3.7 L bench-scale bioreactor.}

Bench-scale fermentation for MPA production was carried out in a $3.7 \mathrm{~L}$ bench-scale bioreactor (Bioengineering) having 2.5 L of working volume. The bench scale bioreactor (Bioengineering) system's main specifications are as follows: Impeller used in $3.7 \mathrm{~L}$ fermentor for proper mixing of nutrients was bottom driven type, have turbine of $2 \mathrm{~mm}$ thickness. The number of impellers used in the fermentor was 2, having 6 numbers of blades in each impeller. A ring-type sparger with 12 holes of $78 \mathrm{~mm}$ diameter was used for proper aeration. 4 numbers of baffles of $14 \mathrm{~mm}$ width were used in the fermentor. The working volume of the fermentor was $2.5 \mathrm{~L}$.

The controllers for all important parameters such as agitation speed, $\mathrm{pH}$, dissolved oxygen, and temperature were equipped in a bioreactor. A pre-installed software program for fermentation (BioSCADA, flexible software that is adaptable to user requirements) in the system was used for online monitoring and control of the fermentation process. To adjust the dissolved oxygen concentration level of the fermentation broth before the inoculation at $100 \%$, 
the air was used as the inlet gas at the fermentation temperature. A polarographic type dissolved oxygen probe (Mettler-Toledo, Switzerland) with the replaceable membrane was used to analyze the dissolved oxygen concentration. It is connected to a dissolved oxygen analyzer of the computer-controlled fermentation system. A sterilizable $\mathrm{pH}$ electrode (Mettler-Toledo, Switzerland) was used to measure the culture broth's $\mathrm{pH}$ value. For the $3.7 \mathrm{~L}$ fermentor system, the supplied air, exhaust pipes, and other parts were sterilized by autoclave. A steam-heated jacket sterilized the culture vessel and broth.

\subsection{Cultivation method.}

Batch, fed-batch, and continuous fermentation were performed to produce mycophenolic acid in a $3.7 \mathrm{~L}$ bioreactor (bioengineering) with $2.5 \mathrm{~L}$ of working volume. The $5 \%(\mathrm{v} / \mathrm{v})$ of the four-day-old culture of microorganism was used as inoculum. The medium $\mathrm{pH}$ was initially set at 5.5 , the incubation temperature of the bioreactor was kept at $28{ }^{\circ} \mathrm{C}$, and the agitation speed and aeration rate of the bioreactor were $200 \mathrm{rpm}$ and $2 \mathrm{vvm}$, respectively. Intermittently, $5 \mathrm{~mL}$ of sample was collected aseptically to examine dry cell weight, product, and substrate concentration.

\section{Results and Discussion}

\subsection{Production kinetics studies of MPA using the batch fermentation process.}

The batch fermentation process was performed to produce mycophenolic acid in a 3.7 L continuous stirred tank bioreactor for ten days. In batch fermentation, the complete medium was used, as stated before. Figure 1 indicates the variation in product formation, dry cell weight, and concentration of the substrate. The maximum consumption of glucose was observed from $24 \mathrm{~h}$ to $144 \mathrm{~h}$ of the fermentation process, and the growth of the microbial cells increased and reached its maximum at the same time. As the biomass increased, glucose was consumed rapidly. The dissolved oxygen concentration dropped to almost below the critical point about $96 \mathrm{~h}$ due to rapid growth and glucose intake, despite the increased agitation speed in attempts to boost the supply of oxygen. After the biomass growth had ceased, MPA concentration started to rise. This confirms that the MPA is a secondary metabolite. The biosynthesis of MPA was mainly initiated from $120 \mathrm{~h}$ onwards. Nearly all glucose was consumed at about 240 hours and, thus, oxygen demand decreased, and the dissolved oxygen concentration in the bioreactor started to increase. At the end of fermentation, the maximum MPA concentration of $1.55 \mathrm{~g} / \mathrm{L}$ was reached.

Figure 2 illustrates the broth's physical presence at different stages of the bioreactor's culture during the growth of Penicillium brevicompactum. During the sterilization process of the fermentation media, some of the glucose was caramelized that naturally happens, and due to caramelization of glucose, the color of the medium was initially dark brown. When microbial growth occurs during the fermentation process, the color of the fermentation broth became golden yellowish and gradually converted into a creamy color due to microbial growth. At this stage, almost all the glucose was consumed. As the fungal biomass concentration in suspension increased, the fermentation broth became more viscous over time. This is a very typical characteristic of fermentations that involve the mycelia formation of microfungi. 
- - Glucose Conc (g/L)

- Dissolved Oxygen (\% saturation)

--Dry Cell Weight ( $\mathrm{g} / \mathrm{L})$

$-\triangle-$ MPA Concentration ( $g / L)$

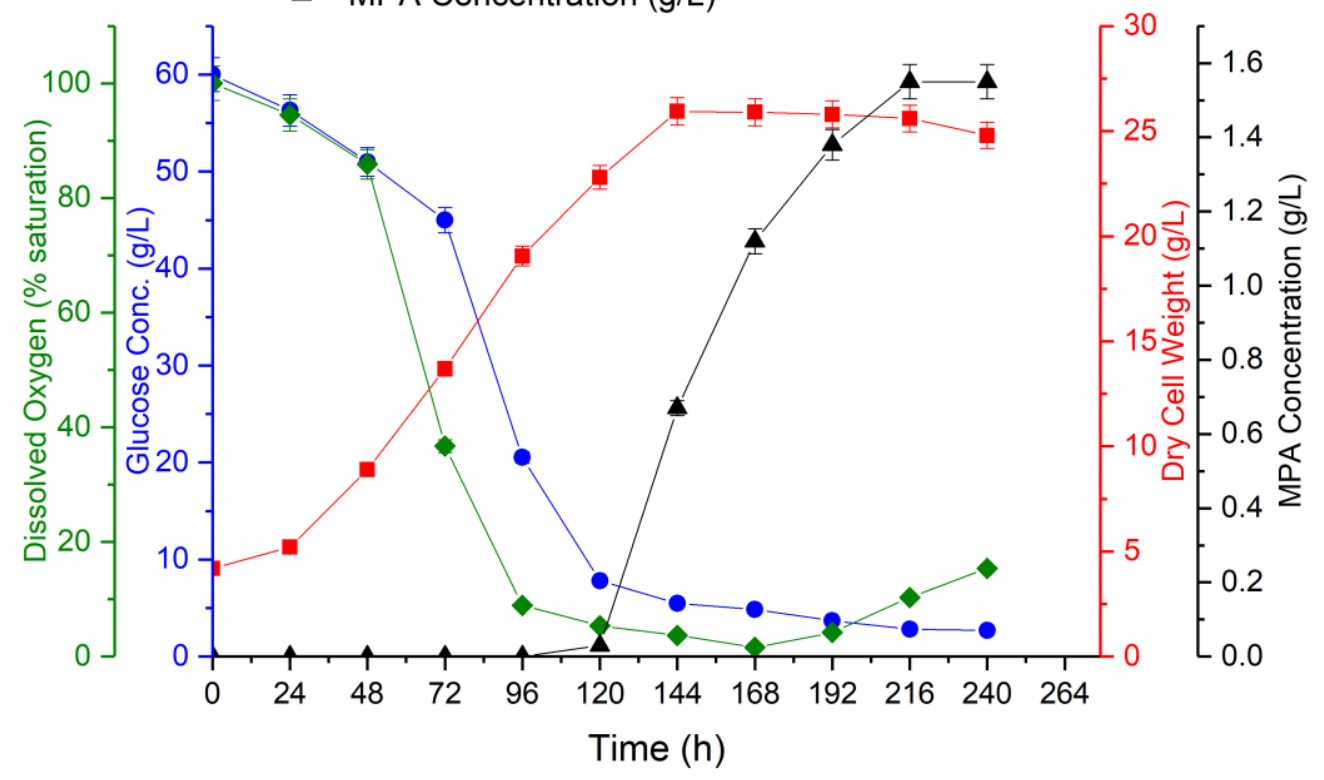

Figure 1. Glucose concentration, dissolved oxygen concentration, dry cell weight, and MPA production profiles in batch fermentation process during MPA production by P. brevicompactum MTCC 549.

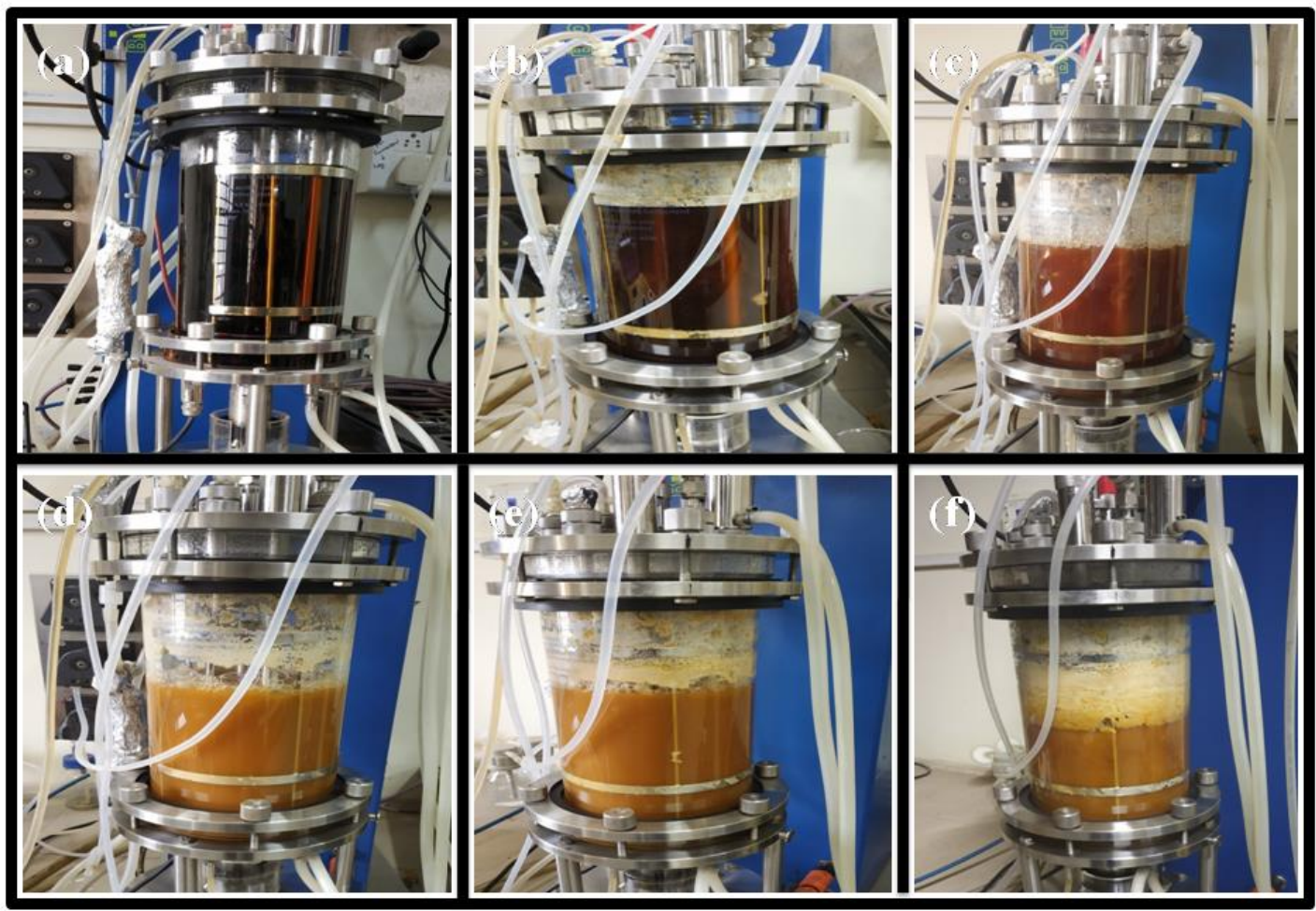

Figure 2. The physical presence of the broth during the growth of Penicillium brevicompactum in the bioreactor: day 1 of culture (a); day 3 of culture (b); day 5 of culture (c); day 7 of culture (d); day 9 culture (e); and day 10 of culture (f).

\subsection{Production kinetics studies of MPA using a fed-batch fermentation process.}

Mycophenolic acid production shows non-growth-associated product formation kinetics. In order to assess the productivity of MPA, the fed-batch cultivation was performed. The Fed-batch procedure was carried out using media with an initial glucose concentration of 
$36 \mathrm{~g} / \mathrm{L}$ in $3.7 \mathrm{~L}$ of continuous stirred tank bioreactor, followed by additions of glucose while maintaining the other variables at a constant level. The medium $\mathrm{pH}$ was initially set to 5.5 , the bioreactor's incubation temperature was $28^{\circ} \mathrm{C}$, the agitation rate of the bioreactor was $200 \mathrm{rpm}$, and the aeration rate was $2 \mathrm{vvm}$ and the fermentation process continued for 12 days. Samples were taken intermittently and examined for cell mass, glucose concentration, and MPA. It was observed that the biomass concentration during the fed-batch fermentation process remained virtually constant and near its maximum value during the entire period due to the addition of the medium. In reference to the earlier batch fermentation experiments, depletion of glucose and the corresponding initiation of idiophase in the fed-batch run were expected. The addition of the supplementary medium began after the initial fermentation time of $96 \mathrm{~h}$. The feeding component and concentration were determined based on specific uptake rates of different nutrients and maintenance energy requirements. The maintenance energy was observed as $0.009 \mathrm{~g}$ substrate/ $\mathrm{g}$ cell mass/ $\mathrm{h}$ in batch fermentation. Glucose additions were made to $15 \mathrm{~g} / \mathrm{L}$ at $96 \mathrm{~h}$ and $144 \mathrm{~h}$ of fermentation based on this maintenance coefficient and substrate consumption profile. The time-course profiles of cell growth, glucose consumption, dissolved oxygen concentration, and mycophenolic acid production by Penicillium brevicompactum in fed-batch mode are shown in Figure 3. In the stationary period, i.e., 120- 288 h, the highest MPA production rate was observed. The measured maximum MPA concentration was 1.91 $\mathrm{g} / \mathrm{L}$.

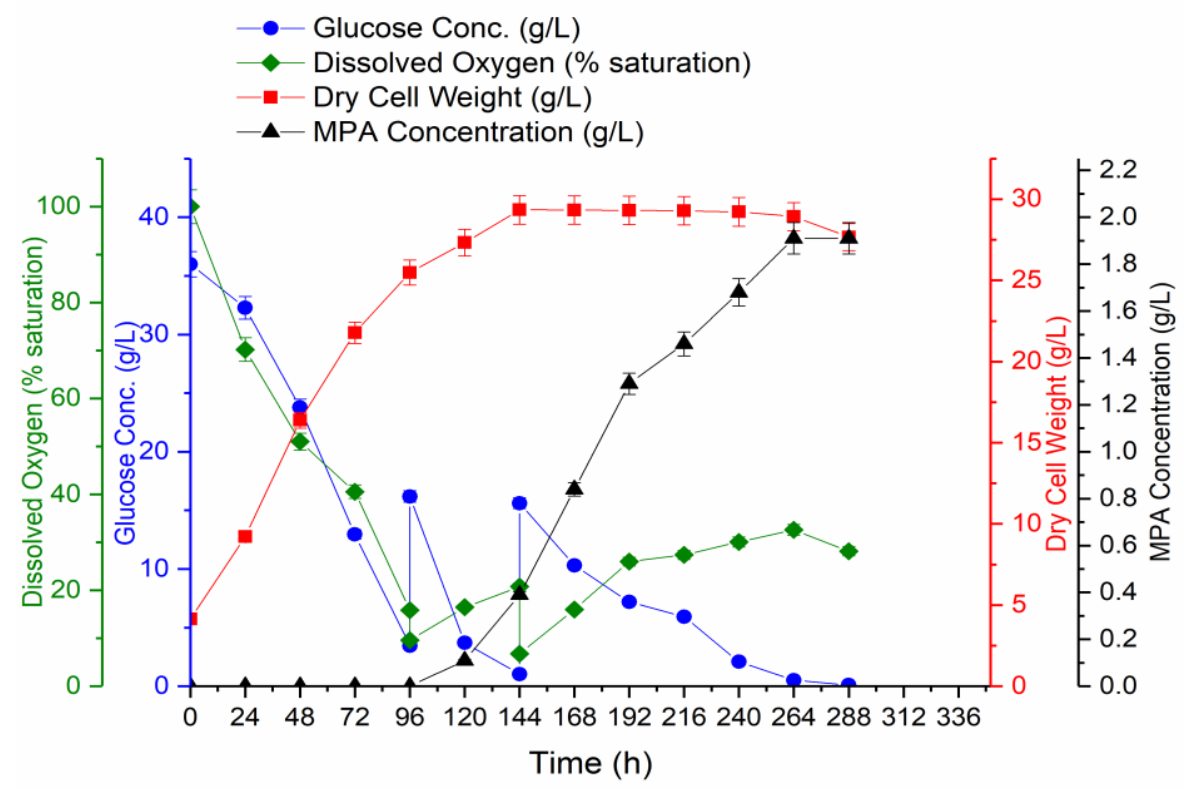

Figure 3. Time-course profiles of biomass growth, glucose consumption, dissolved oxygen concentration, and mycophenolic acid concentration by Penicillium brevicompactum in fed-batch process.

\subsection{Continuous cultivation process of MPA production.}

To study the productivity of MPA in the $3.7 \mathrm{~L}$ stirred tank bioreactor at a temperature of $28{ }^{\circ} \mathrm{C}$, a continuous fermentation process was carried out. The working volume was $2.5 \mathrm{~L}$ in the continuous reactor for cultivation. A two-channeled peristaltic pump was equipped with the bioreactor for feeding the substrate and for effluent withdrawal. The substrate feeding was continuously provided with a constant flow rate, and the effluent was removed with the same flow rate. Samples were examined for dry cell weight, substrate concentration, and mycophenolic acid concentration. Initially, the process was run in batch mode for 72 hours and 
then switched to continuous mode, retaining aseptic conditions. The broth samples were taken every $24 \mathrm{~h}$ of interval and evaluated.

In stirred tank bioreactor, mycophenolic acid production profile using a continuous mode of fermentation was shown in Figure 4. Dilution rate variations from 0.01 to $0.03 \mathrm{~h}^{-1}$ were analyzed for $24 \mathrm{~h}$ each. The effect of the dilution rate on MPA production during steadystate growth in continuous culture was studied. Initially, the fermentation process was conducted as batch fermentation, after which when the microbial growth reached a steadystate, the batch fermentation was transferred to continuous fermentation mode, and after $72 \mathrm{~h}$, the substrate feeding was started for each and every dilution rate. The optimum dilution rate was found to be $0.015 \mathrm{~h}^{-1}$ for the continuous MPA production process.

The efficient production of metabolites is possible by maximizing the rate of output under given conditions. Figure 4 indicates that a reduction in the mycophenolic acid concentration was found with rising dilution rates. The improved productivity of mycophenolic acid from dilution rate 0.01 to $0.015 \mathrm{~h}^{-1}$ was observed. A further rise in the rate of dilution has contributed to a decline in productivity. The mycophenolic acid concentration of culture broth decreased at a higher dilution rate than $0.015 \mathrm{~h}^{-1}$. It might be due to the production of mycophenolic acid was a slow process. Also, it may be indicated that mycophenolic acid production follows non-growth-associated production kinetics. The results suggested that mycophenolic acid's optimal production can be achieved at a dilution rate of $0.015 \mathrm{~h}^{-1}$ in stirred tank bioreactor, and mycophenolic acid concentration was observed to be $1.67 \mathrm{~g} / \mathrm{L}$. The optimal productivity of mycophenolic acid was observed to be $0.025 \mathrm{~g} / \mathrm{L} / \mathrm{h}$. The outcome indicates that the dilution rate should be low to achieve a high mycophenolic acid production rate and yields. At a dilution rate of $0.03 \mathrm{~h}^{-1}$, the cell washout limiting condition prevailed. It has also been found that a keen deviation in substrate concentration in the fermentation broth occurs at the dilution rate near the washout condition. In continuous culture, the overall bioreactor productivity was greater than in batch and fed-batch culture.

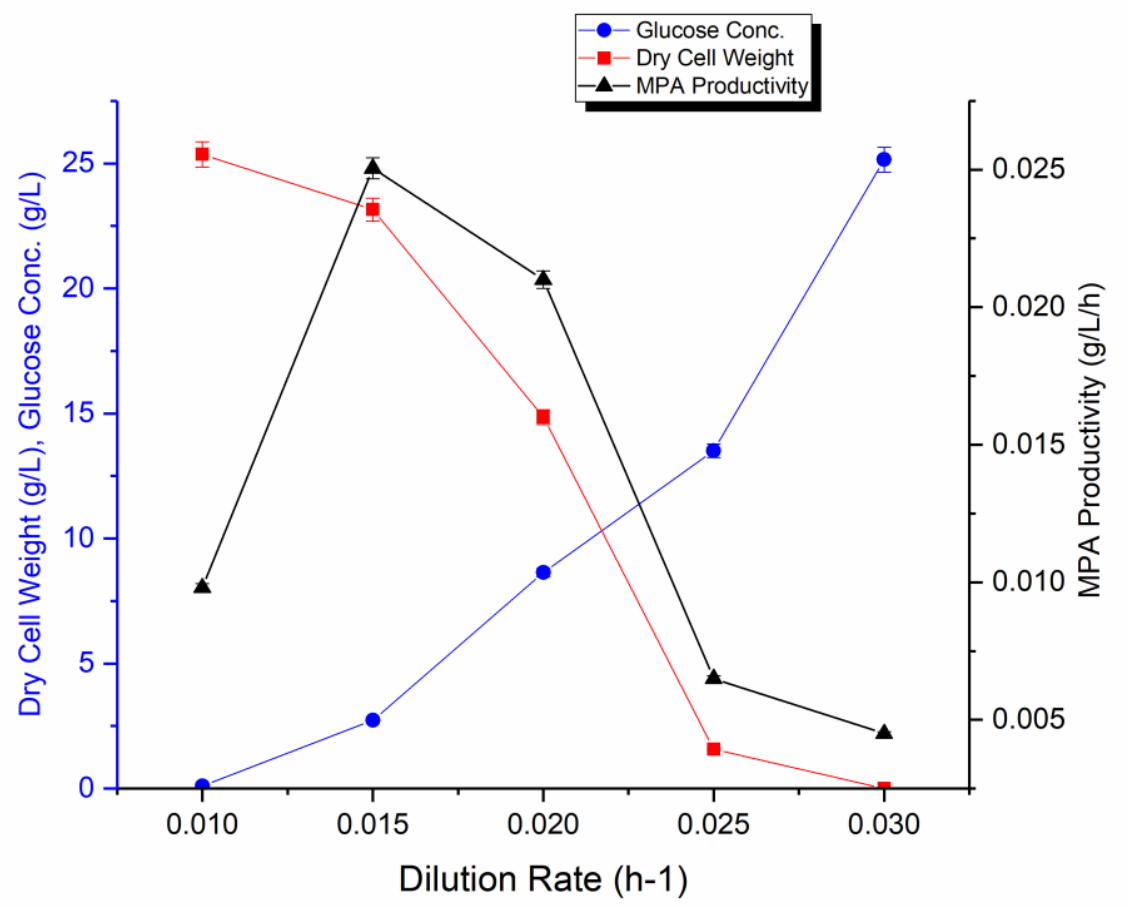

Figure 4. Dry cell weight, glucose concentration, and mycophenolic acid concentration during the continuous mode of fermentation of Penicillium brevicompactum at different dilution rates. 
3.4. Comparison of the batch, fed-batch, and continuous fermentation process for mycophenolic acid production.

The method leading to MPA production is sequential in the batch mode of mold cultivation, i.e., they exhibit separate physiological phases, i.e., the development period (Tropophase) followed by a production phase (Idiophase). Microbial growth was observed up to $120 \mathrm{~h}$, followed by the production process of the MPA, which lasted until the end of fermentation.

The fed-batch analysis was carried out to calculate the residual glucose levels for the feeding profile. The result obtained from fed-batch fermentation defined optimal production feeding conditions and shows how MPA production was successfully enhanced by first successive fermentation conditions for mycelia and secondary management of feeding conditions without catabolic repression, as may be seen in the feeding of glucose as a substrate.

The continuous mode can be proposed as superior regarding productivity over the other two approaches analyzed with the comparative study of MPA production using various modes.

MPA concentration and productivity during MPA production in batch, fed-batch, and continuous cultivation modes are summarized in Table 1. Compared to other cultivation types, productivity was found to be the highest in the continuous cultivation process. In fed-batch fermentation, on the other hand, MPA production was observed to be highest.

Table 1. MPA concentration and productivity during a batch, fed-batch, and continuous fermentation in $3.7 \mathrm{~L}$ stirred tank bioreactor

\begin{tabular}{c|c|c|c} 
S. no. & Cultivation Mode & MPA Concentration $(\mathbf{g} / \mathbf{L})$ & MPA Productivity $(\mathbf{g} / \mathbf{L} / \mathbf{h})$ \\
\hline $\mathbf{1 .}$ & Batch & 1.55 & 0.006 \\
\hline $\mathbf{2 .}$ & Fed Batch & 1.91 & 0.007 \\
\hline 3. & Continuous & 1.67 & 0.025
\end{tabular}

\section{Conclusions}

A comparative analysis of the production and productivity of MPA in various cultivation modes was carried out. In the continuous fermentation mode, the maximum MPA productivity of $0.025 \mathrm{~g} / \mathrm{L} / \mathrm{h}$ was obtained, while the fed-batch cultivation produced the highest concentration of $1.91 \mathrm{~g} / \mathrm{L}$ MPA. For the stationary phase, i.e., 120-240 h, the MPA production rate was observed to be the best. Also, MPA production can be increased in fed-batch cultivation, holding the cultivation process longer in this phase. The growth rate of the organism was maintained over a long time in the continuous culture.

The rate of MPA accumulation was highest in continuous fermentation, in comparison to the batch mode. In a steady state with continuous culture, the organism was in a stronger adaptive stage. The optimum dilution rate was found to be $0.015 \mathrm{~h}^{-1}$ for the continuous MPA production process. Since MPA productivity was the lowest in batch mode of operation, this cultivation method was the least productive operation method.

\section{Funding}

This research received no external funding.

\section{Acknowledgments}

The authors are thankful to the Central Instrument Facility Centre (CIFC) and the Department of Chemical Engineering IIT (BHU) Varanasi, India, for providing technical help. 


\section{Conflicts of Interest}

The authors would like to state that they have no potential conflict of interest regarding this article.

\section{References}

1. Zhou, Y.; Han, L.-R.; He, H.-W.; Sang, B.; Yu, D.-L.; Feng, J.-T.; Zhang, X. Effects of agitation, aeration and temperature on production of a novel glycoprotein GP-1 by Streptomyces kanasenisi ZX01 and scaleup based on volumetric oxygen transfer coefficient. Molecules 2018, 23, https://doi.org/10.3390/molecules23010125.

2. Patel, G.; Patil, M.D.; Tangadpalliwar, S.; Nile, S.H.; Garg, P.; Kai, G.; Banerjee, U.C. Machine Learning Modeling for Ultrasonication-Mediated Fermentation of Penicillium brevicompactum to Enhance the Release of Mycophenolic Acid. Ultrasound in Medicine \& Biology 2021, 47, 777-786, https://doi.org/10.1016/j.ultrasmedbio.2020.11.018.

3. Freedman, R.; Yu, R.; Sarkis, A.W.; Hedstrom, L. A structural determinant of mycophenolic acid resistance in eukaryotic inosine 5'-monophosphate dehydrogenases. Protein Science 2020, 29, 686-694, https://doi.org/10.1002/pro.3766.

4. Weißbarth, G.; Wiesen, M.H.; Fietz, C.; Streichert, T.; Ehren, R.; Weber, L.T.; Müller, C. Pharmacodynamic Monitoring of Mycophenolic Acid Therapy: Improved Liquid Chromatography-Tandem Mass Spectrometry Method for Measuring Inosin-5'-Monophosphate Dehydrogenase Activity. Therapeutic drug monitoring 2020, 42, 282-288, https://doi.org/10.1097/FTD.0000000000000688.

5. El-Sayed, E.-S.R.; Ahmed, A.S.; Ismaiel, A.A. Agro-industrial byproducts for production of the immunosuppressant mycophenolic acid by Penicillium roqueforti under solid-state fermentation: Enhanced production by ultraviolet and gamma irradiation. Biocatalysis and agricultural biotechnology 2019, 18, https://doi.org/10.1016/j.bcab.2019.01.053.

6. Patel, G.; Thakur, N.S.; Kushwah, V.; Patil, M.D.; Nile, S.H.; Jain, S.; Banerjee, U.C.; Kai, G. Liposomal delivery of mycophenolic acid with quercetin for improved breast cancer therapy in SD rats. Frontiers in Bioengineering and Biotechnology 2020, 8, https://doi.org/10.3389/fbioe.2020.00631.

7. Wang, G.; Ye, Q.; Huang, Y.; Lu, J.; Xu, H.; Li, Z. Population pharmacokinetics of mycophenolic acid in pediatric patients with juvenile dermatomyositis and optimization of limited sampling strategy. Xenobiotica 2021, 51, 167-176, https://doi.org/10.1080/00498254.2020.1819579

8. Muth, W.; Nash, C. Biosynthesis of mycophenolic acid: purification and characterization of S-adenosyl-Lmethionine: demethylmycophenolic acid O-methyltransferase. Antimicrobial agents and chemotherapy 1975, 8, 321-327, https://doi.org/10.1128/AAC.8.3.321.

9. Min, C.; Dong, H.; Liu, X.; Zhang, Z. Screening and identification of a Penicillium brevicompactum strain isolated from the fruiting body of Inonotus obliquus and the fermentation production of mycophenolic acid. Annals of Microbiology 2019, 69, 1351-1360, https://doi.org/10.1007/s13213-019-01517-z.

10. Mouhamadou, B.; Sage, L.; Périgon, S.; Séguin, V.; Bouchart, V.; Legendre, P.; Caillat, M.; Yamouni, H.; Garon, D. Molecular screening of xerophilic Aspergillus strains producing mycophenolic acid. Fungal biology 2017, 121, 103-111, https://doi.org/10.1016/j.funbio.2016.10.001.

11. Puel, O.; Tadrist, S.; Galtier, P.; Oswald, I.P.; Delaforge, M. Byssochlamys nivea as a source of mycophenolic acid. Applied and environmental microbiology 2005, 71, 550553,https://doi.org/10.1128/AEM.71.1.550-553.2005.

12. Kitchin, J.E.S.; Pomeranz, M.K.; Pak, G.; Washenik, K.; Shupack, J.L. Rediscovering mycophenolic acid: a review of its mechanism, side effects, and potential uses. Journal of the American Academy of Dermatology 1997, 37, 445-449,https://doi.org/10.1016/S0190-9622(18)30747-3.

13. Badrick, A.C.; Hanson, G.R.; Jones, C.E. Chaperoning the immunosuppressant mycophenolic acid through the gastrointestinal tract: a role for copper. Applied Magnetic Resonance 2009, 36, https://doi.org/10.1007/s00723-009-0021-7.

14. Rahman, A.N.A.; Tett, S.E.; Staatz, C.E. Clinical pharmacokinetics and pharmacodynamics of mycophenolate in patients with autoimmune disease. Clinical pharmacokinetics 2013, 52, 303331,https://doi.org/10.1007/s40262-013-0039-8.

15. de Winter, B.C.; van Gelder, T. Therapeutic drug monitoring for mycophenolic acid in patients with autoimmune diseases. Oxford University Press: 2008;https://doi.org/10.1093/ndt/gfn497.

16. von Borstel, A.; Abdulahad, W.H.; Dekkema, G.; Rutgers, A.; Stegeman, C.A.; Veldman, J.; Heeringa, P.; Sanders, J.S. Mycophenolic acid and 6-mercaptopurine both inhibit B-cell proliferation in granulomatosis with polyangiitis patients, whereas only mycophenolic acid inhibits B-cell IL-6 production. Plos one 2020, 15, https://doi.org/10.1371/journal.pone.0235743.

17. de la Torre, P.; Fernández-de la Torre, M.; Flores, A.I. Premature senescence of placental decidua cells as a possible cause of miscarriage produced by mycophenolic acid. Journal of Biomedical Science 2021, 28, 114,https://doi.org/10.1186/s12929-020-00704-4. 
18. Zhang, W.; Du, L.; Qu, Z.; Zhang, X.; Li, F.; Li, Z.; Qi, F.; Wang, X.; Jiang, Y.; Men, P. Compartmentalized biosynthesis of mycophenolic acid. Proceedings of the National Academy of Sciences 2019, 116, 1330513310,https://doi.org/10.1073/pnas.1821932116.

19. Alani, F.; Grove, J.A.; Anderson, W.A.; Moo-Young, M. Mycophenolic acid production in solid-state fermentation using a packed-bed bioreactor. Biochemical Engineering Journal 2009, 44, 106110,https://doi.org/10.1016/j.bej.2008.11.005.

20. Ardestani, F.; Fatemi, S.S.-a.; Yakhchali, B.; Hosseyni, S.M.; Najafpour, G. Evaluation of mycophenolic acid production by Penicillium brevicompactum MUCL 19011 in batch and continuous submerged cultures. Biochemical Engineering Journal 2010, 50, 99-103,https://doi.org/10.1016/j.bej.2010.03.008.

21. Shigesaka, M.; Ito, T.; Inaba, M.; Imai, K.; Yamanaka, H.; Azuma, Y.; Tanaka, A.; Amuro, H.; Nishizawa, T.; Son, Y. Mycophenolic acid, the active form of mycophenolate mofetil, interferes with IRF7 nuclear translocation and type I IFN production by plasmacytoid dendritic cells. Arthritis Research \& Therapy 2020, 22, 1-11,https://doi.org/10.1186/s13075-020-02356-z.

22. Mahmoudjanlou, Y.; Dahlmann, T.A.; Kück, U. Molecular analysis of mating type loci from the mycophenolic acid producer Penicillium brevicompactum: Phylogeny and MAT protein characterization suggest a cryptic sexual life cycle. Fungal biology 2020, 124, 821833,https://doi.org/10.1016/j.funbio.2020.07.006.

23. Rodríguez-Gómez, F.J.; Valdelamar, M.P.; Vazquez, A.E.; Perez, P.D.V.; Mata, R.; Miralrio, A.; Castro, M. Mycophenolic acid as a corrosion inhibitor of carbon steel in 3\% wt. $\mathrm{NaCl}$ solution. An experimental and theoretical study. Journal of Molecular Structure 2019, 1183, 168181,https://doi.org/10.1016/j.molstruc.2018.12.035.

24. Rong, Y.; Kiang, T.K. Mechanisms of metabolism interaction between p-cresol and mycophenolic acid. Toxicological Sciences 2020, 173, 267-279,https://doi.org/10.1093/toxsci/kfz231.

25. Arns, W.; Cibrik, D.M.; Walker, R.G.; Mourad, G.; Budde, K.; Mueller, E.A.; Vincenti, F. Therapeutic drug monitoring of mycophenolic acid in solid organ transplant patients treated with mycophenolate mofetil: review of the literature $\quad$ Transplantation $2006, \quad 82, \quad 1004$ 1012,https://doi.org/10.1097/01.tp.0000232697.38021.9a.

26. Peters, F.S.; Peeters, A.; Hofland, L.J.; Betjes, M.G.; Boer, K.; Baan, C.C. Interferon-gamma DNA methylation is affected by mycophenolic acid but not by tacrolimus after T-cell activation. Frontiers in immunology 2017, 8, https://doi.org/10.3389/fimmu.2017.00822.

27. Allison, A.C.; Eugui, E.M. Mycophenolate mofetil and its mechanisms of action. Immunopharmacology 2000, 47, 85-118,https://doi.org/10.1016/S0162-3109(00)00188-0.

28. Gillot, G.; Jany, J.-L.; Dominguez-Santos, R.; Poirier, E.; Debaets, S.; Hidalgo, P.I.; Ullan, R.V.; Coton, E.; Coton, M. Genetic basis for mycophenolic acid production and strain-dependent production variability in Penicillium roqueforti. Food microbiology 2017, 62, 239-250,https://doi.org/10.1016/j.fm.2016.10.013.

29. Zhang, W.; Cao, S.; Qiu, L.; Qi, F.; Li, Z.; Yang, Y.; Huang, S.; Bai, F.; Liu, C.; Wan, X. Functional characterization of $\mathrm{MpaG}^{\prime}$, the O-methyltransferase involved in the biosynthesis of mycophenolic acid. Chembiochem 2015, 16, 565-569,https://doi.org/10.1002/cbic.201402600.

30. Xu, Z.-N.; Yang, S.-T. Production of mycophenolic acid by Penicillium brevicompactum immobilized in a rotating fibrous-bed bioreactor. Enzyme and microbial technology 2007, 40, 623628,https://doi.org/10.1016/j.enzmictec.2006.05.025.

31. Patel, G.; Patil, M.D.; Soni, S.; Khobragade, T.P.; Chisti, Y.; Banerjee, U.C. Production of mycophenolic acid by Penicillium brevicompactum - a comparison of two methods of optimization. Biotechnology Reports 2016, 11, 77-85,https://doi.org/10.1016/j.btre.2016.07.003.

32. Wei, Z.-H.; Chen, N.; Li, Y.-J.; Fan, Q.-L.; Yu, T.-F.; Wang, K.-X.; Dong, B.-T.; Fan, E.-Y.; Yuan, P.-L.; $\mathrm{Hu}, \mathrm{G} .-\mathrm{W}$. Glucose fed-batch integrated dissolved oxygen control strategy enhanced polysaccharide, total triterpenoids and inotodiol production in fermentation of a newly isolated Inonotus obliquus strain. Process Biochemistry 2018, 66, 1-6,https://doi.org/10.1016/j.procbio.2018.01.006.

33. Parashar, D.; Satyanarayana, T. Enhancing the production of recombinant acidic $\alpha$-amylase and phytase in Pichia pastoris under dual promoters [constitutive (GAP) and inducible (AOX)] in mixed fed batch high cell

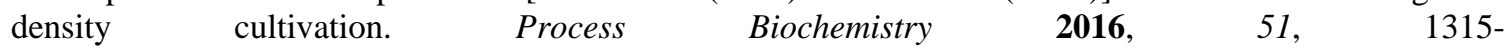
1322,https://doi.org/10.1016/j.procbio.2016.07.027.

34. Dong, Y.; Xu, R.; Wang, L.; Zhang, J.; Bai, C.; Sun, A.; Wei, D. A combined feeding strategy for enhancing mycophenolic acid production by fed-batch fermentation in Penicillium brevicompactum. Process Biochemistry 2015, 50, 336-340,https://doi.org/10.1016/j.procbio.2014.12.023.

35. Bang, H.B.; Lee, K.; Lee, Y.J.; Jeong, K.J. High-level production of trans-cinnamic acid by fed-batch cultivation of Escherichia coli. Process Biochemistry 2018, 68, 3036,https://doi.org/10.1016/j.procbio.2018.01.026.

36. Salehmin, M.; Annuar, M.; Chisti, Y. High cell density fed-batch fermentation for the production of a microbial lipase. Biochemical Engineering Journal $2014, \quad 85, \quad 8$ 14,https://doi.org/10.1016/j.bej.2014.01.006. 
37. Birol, G.; Ündey, C.; Cinar, A. A modular simulation package for fed-batch fermentation: penicillin production. Computers \& chemical engineering 2002, 26, 1553-1565,https://doi.org/10.1016/S00981354(02)00127-8.

38. Soyaslan, E.Ş.; Çalık, P. Enhanced recombinant human erythropoietin production by Pichia pastoris in methanol fed-batch/sorbitol batch fermentation through pH optimization. Biochemical Engineering Journal 2011, 55, 59-65,https://doi.org/10.1016/j.bej.2011.03.007.

39. Arnau, C.; Casas, C.; Valero, F. The effect of glycerol mixed substrate on the heterologous production of a Rhizopus oryzae lipase in Pichia pastoris system. Biochemical Engineering Journal 2011, 57, 3037,https://doi.org/10.1016/j.bej.2011.08.004.

40. Anand, S.; Srivastava, P. Optimization Strategies for Purification of Mycophenolic Acid Produced by Penicillium brevicompactum. Applied biochemistry and biotechnology 2020, 191, 867880,https://doi.org/10.1007/s12010-019-03204-w.

41. Miller, G.L. Use of dinitrosalicylic acid reagent for determination of reducing sugar. Analytical chemistry 1959, 31, 426-428,https://doi.org/10.1021/ac60147a030. 